\title{
Assessing the Metacognitive Awareness of Online Reading Strategies among Pre- University Students
} \author{
International Islamic University Malaysia \\ zaidatulakmal@iium.edu.my \\ ISMAIL SHEIKH AHMAD \\ Kulliyah of Education \\ International Islamic University Malaysia \\ drismail@iium.edu.my \\ MOHD SHUKRI NORDIN \\ Kulliyah of Education \\ International Islamic University Malaysia \\ nmshukri@iium.edu.my \\ ZAINURIN ABDUL RAHMAN \\ Kulliyah of Education \\ International Islamic University Malaysia \\ zainurin@iium.edu.my
}

ZAIDATUL AKMAL BINTI ABD HAMID (corresponding author) Center for Languages and Pre-University Academic Development (CELPAD)

\begin{abstract}
To achieve successful comprehension, a student has to be fully responsible of their own reading. However, being able to read proficiently carries a greater meaning now as more online materials are involved. Many students have been discovered to have difficulties mastering these non-linear readings as they require more sophisticated strategies compared to conventional linear readings. It is believed that being aware of one's strategies could improve the quality of their comprehension and due to that, it is the objective of this study to find out the metacognitive online reading strategy awareness of the participants involved by using Survey of Online Reading Strategies (OSORS) established by Anderson (2003). 495 pre-university students in a Malaysian public university were chosen to be the participants of this study. At the time of the study, they were taking English Language course and English is their second language. From the study, it was discovered that all the participants were aware of most of the online reading strategies but with a very different level of awareness. The strategies under the Problem Solving (PROB) strategy was the highest and this category involves the use of specific techniques when readers encounter problems while reading online. The students involved portrayed their least involvement with the strategies under Support Strategy (SUP) where tools such as live chatting, note taking, and using pictures and graphs are used in assisting their online reading. Due to the inconsistency in the level of awareness discovered in the findings, it is concluded that metacognitive online reading strategies need to be included in the teaching curriculum and teachers too need to be aware and be an expert in utilising the strategies.
\end{abstract}

Keywords: Online Reading, Metacognitive Online Reading Strategies, English as a Second Language, PreUniversity Students

This work is licensed under the terms of the Creative Commons Attribution (CC BY) (https://creativecommons.org/licenses/by/4.0/). 
IJoLLT Vol, 3, No. 2( September) 2020

eISSN: 2637-0484

Published online: October 2020

To cite this article: Hamid, Z. A. A., Ahmad, I. S., Nordin, M. S. \& Rahman, Z. A. (2020). Assessing the Metacognitive Awareness of Online Reading Strategies among Pre-University Students. International Journal of Language, Literacy and Translation 3(2), 19-31. https://doi.org/10.36777/ijollt2020.3.2.035

To link to this article: https://doi.org/10.36777/ijollt2020.3.2.035 


\section{INTRODUCTION}

Technology is part and parcel of our everyday life. It cannot be seen as something that is only reserved for the 'tech-savvy'. As of December 2019, over 4.5 billion individuals had access to the Internet which was about 58\% of the world population (Internetworldstats, 2019). Incorporating technology in education is now essential. With the current situation, where we are fighting one of the worst pandemics that has ever happened, Covid-19, online teaching and learning have become part of the education world. The practices of reading and writing have developed, which is consistent with the number of technology users that has increased, particularly in the area of reading (Coiro, 2011). This is in line with how sophisticated and resourceful this new technology is. The ability to read in this digital era is not just the ability to master the skills of reading printed materials but also electronic reading materials. Online reading has become a common situation for most people, but the effectiveness and efficiency of digital reading is uncertain (Brun-Mercer, 2019). Most of the young generations today are widely exposed to the Internet, however they have never received formal trainings on how to effectively read digital materials (Brun-Mercer, 2019). Carioli and Peru (2019) again confirmed this statement that most young readers are not trained systematically on the strategies required for online text reading. They also stated the claim that the impressive ability of the young digital natives is overrated.

Due to the nature of hypertext reading for example in the Internet, the readers nowadays are exposed to a situation where they have to be actively interacting with the information and they also need to have the ability to identify and choose which information they feel fits their reading purposes. Readers have full authority in deciding their reading path, which information they would like to access, and in which order the information is viewed and gathered. According to Azmuddin, Nor and Hamat (2017), online reading refers to hypertext that is presented on electronic devices which comprises of hyperlinks and nodes that are connected, which many believe to be a more complex structure if compared to offline text.

It is believed that there are certain skills used when reading offline that overlap with online reading process, but it is not sufficient when no specific skills for online reading are incorporated (Incecay, 2013). Coiro and Dobler (2007) wrote that this different reading environment demands different skills from the readers where understanding website structure and having knowledge of the search engine used is a must for them to experience meaningful reading. To ensure a genuine and complete comprehension of the materials, skills that are used in a traditional reading situation is not sufficient; more diverse strategies are needed (Carioli and Peru, 2019). In the situation where online teaching is practiced, and when teachers are only monitoring the students remotely, being aware of the strategies needed by the students when they read digitally is essential.

\section{THE CURRENT SITUATION}

The internet has become one of the key sources of materials for teachers and learners in presentday English language teaching and learning as it provides wide arrays of materials that can be utilised for reading activities. According to Chen (2009), the Internet has changed the nature of reading which provides unlimited resources for readers. Park, Yang and Hsieh (2014) stated that the variety of reading materials available online has made the foreign and second language 
learners of English turn to the Internet as their major source of learning input. They also believed that availability of multiple support resources and fast access which assist comprehension is making online reading more attractive. In the chosen institution for this study, using online platforms and materials in the teaching and learning process are also seen as very important. Teachers are always encouraged to utilise e-learning in their teaching.

In light of the COVID-19 disease, most educational institutions all over the world have been forced to close. The world of education is going through massive changes where most are opting for online classes. It is inevitable that many challenges are encountered; from the institutions, the administrators, the teachers and to the students, the main stakeholders themselves.

This brings a situation that we need to look at. When using online materials for learning, readers have to take charge of their own reading; to organise and to control the process and due to the characteristics of the Internet, readers might be lost in the cyber-space as they have to be involved in different types of activities simultaneously. As stated by Wu (2014), digital reading such as that of the Internet is unique as it involves hyperlinks and search engines, and due to the non-linearity, it may also become the origin of navigation problem that later can cause surface readings, distractions and disorientations among readers. From the statement, it can be inferred that hypertext involves very rich information, and this could lead to difficulties or even failures in achieving comprehension. In order to understand clearly the acquisition of knowledge from hypertext, it is imperative to find out further how readers involve actively with the many layers of information within a hypertext environment (Puntambekar, Sullivan \& Hubscher, 2013). In the theory of new literacies of online research and comprehension, how readers locate, evaluate, and synthesise online information are crucial when they are reading.

Teachers need to be aware that finding information online successfully does not happen automatically. It needs organised thinking, more than what most thought. When reading online, readers need to have self-directed skills in selecting and organising the materials they encounter (Naumann \& Salmeron, 2016). This is where the concept of metacognition comes into the picture.

\section{METACOGNITIVE AND ONLINE READING}

In 1979, metacognition was first used by Flavell and was defined as being aware of ones' thinking and being able to control the process of thinking. According to Pintrich, Wolters and Baxter (2000), there are two types of knowledge when metacognitive is discussed; knowledge of strategies and conditional knowledge of when and why to use these strategies.

Stylianou and Puntambekar (2003) believed that the understanding of one's own cognitive process or metacognition has proven to be the important source of understanding and comprehending a text. This is fully supported by Incecay (2013) where it stated that metacognitively aware readers are more conscious of their own reading processes and the demands of the task. As cited in Ulu and Ulusoy (2019), through metacognition awareness, the reader uses appropriate strategies in order to have meaningful reading experience and also identifies the points which are not understood (Johnson, Freedman and Thomas, 2008).

Azmuddin, et al. (2017) wrote that online reading is associated with the skills to navigate between hypertexts, and the practice of metacognitive awareness is part of the process. When readers are aware of the reading strategies that they practice while reading, it is called metacognitive awareness (Sheorey \& Mokhtari, 2001). Another explanation of being 
metacognitively aware is when readers are totally alert of the whole process of reading and they have the ability to set the reading goals by themselves. Having this awareness is also a method for readers and learners to have the ability to plan, regulate and manage their online reading. It will assist readers to decide on which action to be taken during the process.

Mokhtari and Sheorey (2002) came out with a scale to measure metacognitive awareness of reading strategies for ESL adolescents and adult students. They built the instrument, Survey of Reading Strategies (SORS) to assist teachers as a means to increase the strategy awareness among the readers (Mokhtari \& Sheorey, 2002). Based on this instrument, Anderson (2003) proposed the Online Survey of Reading Strategies (OSORS), an instrument to measure the reading strategy awareness of the readers when they read online. This instrument is divided into three factors and the first is Global Reading Strategies (GLOB) where it involves techniques that are planned when readers monitor and manage their reading experience. All the techniques are intentional and consciously done (Mokhtari \& Sheorey, 2002). The second factor is Problem Solving Strategies (PROB) which are about strategies that readers utilise when they encounter difficulties during their reading activities. The readers focus on finding ways to solve the problems during the process of understanding the materials (Mokhtari and Reichard, 2002). The third factor is Support Reading Strategies (SUP) which involves the utilisation of other materials and resources to assist the comprehension of the reading materials such as charts, videos, and pictures (Mokhtari and Reichard, 2002). Instruments as such are important as they help readers to discover the strengths and weaknesses in their reading strategies.

In a study done by Chiazzese, Ohaviano, Merlo, et al. (2006), they developed a system that stimulates metacognitive and cognitive strategies. While surfing, the students were prompted with metacognitive questions with the objective to improve the awareness of strategies they were using. The system was proven to improve the students' hypertext comprehension. The students in the experimental group also believed that it was helpful as a tool to monitor their online navigation. At the end of the study, it was found that when learners have the ability to plan and control their own online reading as well as the navigation, successful comprehension can be achieved.

Kymes (2007) compared the reading strategies of high school students when they read online and printed materials. The students were discovered to use more strategies when they read online. Strategies they used when reading printed text were also used when they were reading online. However, there were many new strategies that were discovered during their online reading experience. Kymes (2007) also revealed participants' lack of skills and strategies usage when they were engaged with online materials. Therefore, there is a need for special training in order to improve the learners' online reading experiences.

Study on metacognitive strategies is not yet widespread in Malaysia. However, among the first was done by Zailani Jusoh and Liza Abdullah (2015). In this study their objective was to discover the strategies utilised by students from two faculties in a Malaysian public university. The students were in their third semester of their four-year course. The study was also to find whether the students from these two faculties used different strategies. Their study utilised OSORS. They categorised the strategy usage into three which were high, medium, and low. It was found that 16 strategies (44\%) had high frequency of use. $20(56 \%)$ strategies were in the medium range and surprisingly, there was no strategy that fell into the low frequency category. In terms of factors of strategies, PROB was the highest and the lowest was the SUP. At the end of the study, it was also discovered that there was no significant difference in terms of the 
strategies used between students from the two faculties. However, their study focused on experienced tertiary education students rather than high school leavers.

A study conducted by Raihana, Jamaludin, \& Nooreiny (2017) focused on finding the metacognitive strategies of online academic reading materials among students in two public Malaysian universities. The level of strategies for most of the students involved in the research was between moderate and high level. Furthermore, students' language proficiency levels determined the types of strategies that they chose. It was discovered that more strategies are used by the students who had higher level of language proficiency compared to the lower ones who also had poor monitoring skill which is one of the most important strategies for a successful comprehension.

In one of the higher institutions in Indonesia, Heri Mudra (2018) tried to find out the metacognitive strategies in online reading amongst the pre-service teachers. His study also utilised OSORS. From the study, GLOB was the most common factor employed, followed by PROB and SUP. This result is different from the study conducted by Zailani Jusoh and Liza Abdullah (2015) in Universiti Sultan Zainal Abidin (UnisZA) where PROB scored the highest. Besides, Heri Muda also discovered that the learners used variety of strategies to ensure they completed the given online task and also to comprehend the hypertext that was used in the study.

From the literature above, it is proven that many researchers have tried to study further on metacognitive online reading strategies as many believed that being aware of them and using specific strategies when reading online can support better reading comprehension. However, most of the studies done were on undergraduate students. None of the studies involved preuniversity students who had just left high school. Furthermore, none of the studies were done by using a huge number of samples.

Metacognitive awareness should be stressed among the academics as well as the students. This is to ensure that when students start their undergraduate study; they will be better prepared. Undergraduate education is when the students will be exposed more to online reading materials. It is crucial for the academics and the institutions to first be aware about the students' strategies when they read online before engaging the students with huge number of digital learning. It is important to carry out this study as from the result, it will help the teachers and the institutions to prepare the students better when it comes to utilising online materials. As educators, it is important for us to know further about online reading and think about how we can facilitate students with their reading to ensure a meaningful comprehension is achieved (Hodgson, 2010). Therefore, the aim of this research is to study the students' level of metacognitive strategy awareness specifically with regard to online reading.

\section{METHODOLOGY}

This study was conducted on 495, first semester students in Centre for Foundation Studies of a local public university. The sampling procedure was probability sampling where the participants were chosen randomly based on a systematic manner. To ensure that the sample was representative of the population, probability sampling was used where in this method, everyone in the population had equal chance to be included in the study (Walsh \& Ollenburger, 2001). The participants came from variety of faculties and English is their second language. During the semester in which the survey was conducted, all the students were taking English language subject. 
To achieve the objective, Online Survey of Reading Strategies (OSORS) developed by Anderson (2003) was conducted. In this study, a 5-point Likert scale was utilised that ranged from $1=$ I never do this to $5=$ I always do this. This self-report instrument had 38 items and was divided into three factors which are Global Reading Strategies (GLOB), Problem Solving Strategies (PROB) and Support Reading Strategies (SUP).

OSORS is a reliable instrument which had gone through rigorous testing to ensure its reliability in assessing the metacognitive online reading strategies of foreign language learners. The reliability of OSORS are as follows: The Cronbach's alpha for the overall OSORS was .92. The reliability for each of the three subsections was .77 for global reading strategies, .64 for problem-solving strategies, and .69 for support strategies. (Anderson, 2003, p.16)

Anderson (2003) also claimed that OSORS is an instrument that is trusted and furthermore to confirm the reliability, many studies have utilised it in research concerning metacognitive online reading strategies such as by Incecay (2013), Ostovar-Namaghi and Noghabi (2014), and Vaičiūnienė and Užpalienè (2013).

To analyse the data, descriptive analysis was carried out by using SPSS which produced the mean scores and standard deviation. Based on Anderson (2003) classification, the score for each strategy can be classified according to three levels which are high (3.5 or higher), medium (2.5 to $3.4)$ or low (2.4 or lower).

\section{RESULTS AND DISCUSSION}

The data collected from the questionnaire was analysed quantitatively where the mean and the standard deviation for each item are presented. To make sure the result is more organised, the data was divided into three factors and each factor is presented in a descending order. They are Global Reading Strategies (GLOB), Problem Solving Strategies (PROB) and Support Reading Strategies (SUP). The number of each survey item stated in the tables below is based on the sequence presented in the original survey distributed to the participants of the study.

In Table 1, it can be seen that most of the strategies in GLOB had high mean scores where 12 out of 18 strategies have mean scores of more than 3.5. The strategy with the highest mean score was item number 27 , with a mean score of 3.97 . The strategy that followed very closely was item number 5, where the readers claimed to use their prior knowledge to help their comprehension with a mean score of 3.92. There were four strategies that fell under the medium level of mean scores, ranging from 3.45 to 3.09. However, there were two strategies that had very low mean scores which were item number 2, with a mean score of 1.92 and the lowest item number 3 at only 1.63 , which was the lowest. Both of these least favoured strategies involved live chatting.

Table 1.

Global Reading Strategies (N-495)

\begin{tabular}{llcc}
\hline & \multicolumn{1}{c}{ Global Reading Strategies } & Mean & SD \\
\hline 27 & I try to guess what the content of the on-line text is about when I read. & 3.97 & .916 \\
\hline 5 & I think about what I know to help me understand what I read on-line. & 3.92 & .848 \\
\hline 18 & I use tables, figures, and pictures in the on-line text to increase my understanding. & 3.78 & 1.134 \\
\hline 1 & I have a purpose in mind when I read online. & 3.74 & .908 \\
\hline 8 & I think about whether the content of the on-line text fits my reading purpose. & 3.74 & .880 \\
\hline 26 & I check my understanding when I come across new information. & 3.74 & .916
\end{tabular}




\begin{tabular}{lllc}
17 & I read pages on the Internet for academic purposes. & 3.68 & 1.058 \\
\hline 6 & I take an overall view of the on-line text to see what it is about before reading it. & 3.67 & 1.062 \\
\hline 30 & I check to see if my guesses about the on-line text are right or wrong. & 3.64 & .979 \\
\hline 32 & $\begin{array}{l}\text { I scan the on-line text to get a basic idea of whether it will serve my purposes before } \\
\text { choosing to read it. }\end{array}$ & 3.63 & 1.011 \\
\hline 20 & I use context clues to help me better understand what I am reading on-line. & 3.59 & 1.111 \\
\hline 14 & When reading on-line, I decide what to read closely and what to ignore. & 3.53 & 1.068 \\
\hline 33 & I read pages on the Internet for fun. & 3.45 & 1.097 \\
\hline 10 & I review the on-line text first by noting its characteristics like length and & 3.38 & 1.170 \\
& organization. & 3.28 & .923 \\
\hline 24 & I critically analyze and evaluate the information presented in the on-line text. & 3.09 & 1.252 \\
\hline 23 & I use typographical features like bold face and italics to identify key information. & 1.92 & 1.037 \\
\hline 2 & I participate in live chat with other learners of English. & 1.63 & .971 \\
\hline 3 & I participate in live chat with native speakers of English. & & \\
\hline
\end{tabular}

In Table 2, it is very clear that most of the strategies had high mean scores and there was no strategy under PROB that had a low mean score which was below than 2.5. The highest mean score in PROB was 4.45 which was for item number 28 where the readers believed that rereading the hypertext can increase their comprehension. Focusing more on the text when the reading material is complicated is another strategy with a high mean score which was at 4.30. There were eight strategies out of eleven that had high mean scores. The other three strategies were still in the medium level and the strategy with the lowest mean score in Problem Solving Strategy was item number 35 with 3.27 where the readers could differentiate whether what they are reading is a factual statement or just an opinion.

Table 2

Problem Solving Strategies (N-495)

\begin{tabular}{lllc}
\hline & \multicolumn{1}{c}{ Problem Solving Strategies } & Mean & SD \\
\hline 28 & When on-line text becomes difficult, I re-read it to increase my understanding. & 4.45 & .847 \\
\hline 14 & When on-line text becomes difficult, I pay closer attention to what I am reading. & 4.30 & .853 \\
\hline 9 & I read slowly and carefully to make sure I understand what I am reading on-line. & 4.22 & .889 \\
\hline 11 & I try to get back on track when I lose concentration. & 4.21 & .911 \\
\hline 31 & When I read on-line, I guess the meaning of unknown words or phrases. & 3.86 & .996 \\
\hline 19 & I stop from time to time and think about what I am reading on-line. & 3.79 & .838 \\
\hline 13 & I adjust my reading speed according to what I am reading on-line. & 3.75 & 1.015 \\
\hline 22 & I try to picture or visualize information to help remember what I read on-line. & 3.55 & .956 \\
\hline 36 & When reading on-line, I look for sites that cover both sides of an issue. & 3.37 & .989 \\
\hline 34 & I critically evaluate the on-line text before choosing to use information I read on- & 3.31 & .945 \\
& line. & 3.27 & .988 \\
\hline 35 & I can distinguish between fact and opinion in on-line texts. & \\
\hline
\end{tabular}

Table 3 listed that six out of nine strategies under Support Reading Strategies (SUP) had a high level of mean scores and only three strategies had low level of mean scores. Many of the participants were aware that they need to use reference materials to assist their online text comprehension and this item showed a mean score of 4.17. The lowest mean score in this category was 2.67 and it was discovered that not many believed that having a hard copy of the online text and underlining or circling the information can help them to remember the information. It is important to note that there was no strategy that fell under the low level of mean score in SUP. 
IJoLLT Vol, 3, No. 2( September) 2020

eISSN: 2637-0484

Table 3

Support Reading Strategies (N-495)

\begin{tabular}{llcc}
\hline & \multicolumn{1}{c}{ Support Strategies } & Mean & SD \\
\hline 15 & $\begin{array}{l}\text { I use reference materials (e.g. an on-line dictionary) to help me understand what I } \\
\text { read on-line. }\end{array}$ & 4.17 & 1.047 \\
\hline 16 & $\begin{array}{l}\text { When on-line text becomes difficult, I read aloud to help me understand what I } \\
\text { read. }\end{array}$ & 4.11 & 1.096 \\
\hline 38 & $\begin{array}{l}\text { When reading on-line, I think about information in both English and my mother } \\
\text { tongue. }\end{array}$ & 3.90 & 1.122 \\
\hline 25 & I go back and forth in the on-line text to find relationships among ideas in it. & 3.74 & 1.063 \\
\hline 37 & When reading on-line, I translate from English into my native language. & 1.220 \\
\hline 21 & $\begin{array}{l}\text { I paraphrase (restate ideas in my own words) to better understand what I read on- } \\
\text { line. }\end{array}$ & 3.50 & 1.215 \\
\hline 29 & I ask myself questions I like to have answered in the on-line text. & 3.36 & 1.072 \\
\hline 4 & I take notes while reading on-line to help me understand what I read. & 2.93 & 1.234 \\
\hline 12 & $\begin{array}{l}\text { I print out a hard copy of the on-line text then underline or circle information to } \\
\text { help me remember it. }\end{array}$ & 2.67 & 1.277 \\
\hline
\end{tabular}

As listed in Table 4, the top three most used strategies were under PROB where the highest mean score was 4.45. Most participants re-read and gave closer attention to what they were reading when they encountered difficult texts. They also claimed that to ensure they understood what they read, they would read slowly and carefully. This is in line with the study by Kymes (2007) where most of the participants in her study utilized the strategies under PROB quite efficiently. The participants are good problem solvers when they read online. Kymes (2007) also believed that when someone is aware of his own processing information, the loss of concentration, and the need to understand the information deeper, it shows that the person has the ability to control thinking and the ability to think about their thinking. This is an obvious evidence of high level of metacognitive awareness.

The strategies with the lowest mean score by the participants in this study belong to one strategy from SUP and two from GLOB. Not many of the participants believed that printing out the materials and putting notes on the information could help them to remember more. This strategy had a mean score of 2.67 which was still under the medium category. The two lowest had the mean score of below 2.50 which was under the low category and both belonged to GLOB. Both strategies involved live chatting where one is with other learners of English and the other one which is the most unpopular strategy, live chat with native speakers of English. The participants in this study were all Malaysians and they might not have had friends who were native users of English. That might be the cause for the very low mean score for item number 3 .

Table 4

High and Low level of Strategies Used

\begin{tabular}{llcc}
\hline \multicolumn{1}{c}{ Strategies } & Mean & SD \\
\hline HIGH & & & \\
\hline 28 & $\begin{array}{l}\text { When on-line text becomes difficult, I re-read it to increase my understanding. } \\
(\text { PROB })\end{array}$ & 4.45 & .847 \\
\hline 16 & $\begin{array}{l}\text { When on-line text becomes difficult, I pay closer attention to what I am reading. } \\
(\text { PROB })\end{array}$ & 4.30 & .853 \\
\hline 9 & $\begin{array}{l}\text { I read slowly and carefully to make sure I understand what I am reading on-line. } \\
\text { (PROB) }\end{array}$ & 4.22 & .889 \\
\hline LOW & & & \\
\hline
\end{tabular}


12 I print out a hard copy of the on-line text then underline or circle information to $\quad 2.67$

$2.67 \quad 1.277$ help me remember it. (SUP)

\begin{tabular}{|c|c|c|c|}
\hline 2 & $\begin{array}{l}\text { I participate in live chat with other learners of English. } \\
\text { (GLOB) }\end{array}$ & 1.92 & 1.037 \\
\hline 3 & $\begin{array}{l}\text { I participate in live chat with native speakers of English. } \\
\text { (GLOB) }\end{array}$ & 1.63 & .971 \\
\hline
\end{tabular}

To compare between the categories, the mean score for each category was also analysed as tabled below.

Table 5

Metacognitive Online Reading Strategies (N-495)

\begin{tabular}{lll} 
Categories of Strategies & Mean & SD \\
\hline Global Reading Strategies (GLOB) & 3.41 & .494 \\
\hline Problem Solving Strategies (PROB) & 3.84 & .538 \\
\hline Support Strategies (SUP) & 3.56 & .646
\end{tabular}

Table 5 indicates that GLOB had the lowest mean score which was at 3.41 and SD of 0.494 . This shows that GLOB falls under the medium level strategies. The second highest was SUP with a mean score of 3.56 and SD of 0.646 . This strategy reached just slightly above the highlevel marking as it was more than 3.5 based on the Anderson scale (2003). The highest among the category was for PROB which was 3.84 for the mean score and 0.538 as the SD. This category is also considered as a high- level strategy.

This result is in line with the study conducted by Zailani Jusoh and Liza Abdullah (2015) in a Malaysian public university where the students recorded the highest usage of strategies that are under PROB. However, in their study, the category which had the lowest utilization was SUP, whereas for this current study it is GLOB. What has been discovered in this study is totally opposite to what had been reported by Heri Mudra (2018) in his study among the pre-service teachers. In his study, GLOB had the highest mean score, followed by PROB and the category with the least mean score was SUP. The result of these studies might contradict with the current one as the participants have different criteria. Both studies conducted by Zailani Jusoh and Liza Abdullah (2015) and Heri Mudra (2018) involved undergraduate students who had left schools for a couple of years. They are more mature and have more experience with the environment and culture of tertiary education. The participants in this study are foundation students who had just left schools for less than a year and might still be influenced by the learning culture in schools.

\section{CONCLUSION}

This study is aimed to look at the metacognitive online reading strategy awareness among students who were in the first semester of their foundation studies in a public university in Malaysia. From the data collected and analysed, all the students involved were aware of the strategies required for a meaningful online reading but with a different level of importance. The students were found to focus more on problem solving strategies (PROB) where it involves using specific techniques when readers encounter problems while reading online. The students 
involved portrayed their least involvement with the strategies under Support Strategies (SUP) where tools like using special features such as pictures, videos and graphs, having a live chat and taking notes are used to help online reading comprehension. Therefore, there should be initiatives from the institutions and the academics to improve this situation. This is important as it is believed that proficient readers have high usage of metacognitive strategies (Magogwe, 2013). This was also proven by a study from Raihana et al. (2017) where the low proficiency students used fewer strategies in comparison to the ones with better language proficiency.

For future research, further study needs to be done firstly on how to improve the students' awareness on metacognitive online reading strategies as this can lead to more proficient online readers. Before reading, it is beneficial for readers to be aware of the effective strategies used by proficient readers (Mokhtari \& Sheorey, 2002). To improve the students' strategies, teachers also play very important roles. They themselves must be fully equipped with knowledge about metacognition and its utilization in their teachings. Anderson (2003) believed that when he developed OSORS, it was for the teachers to understand and be aware of their students' online reading strategy awareness. Teachers need to fully equip their students with the awareness and trainings when they decide to conduct online learning task. Further studies involving teachers and how to incorporate metacognition in the teaching of language are also fully encouraged.

\section{REFERENCES}

Anderson, N. J. (2003). Scrolling, Clicking, and Reading English: Online Reading Strategies in a Second/Foreign Language. The Reading Matrix, 3(3), 1-15.

Azmuddin, R. A., Nor, N. F. M., \& Hamat, A. (2017). Metacognitive Online Reading and Navigational Strategies by Science and Technology University Students. GEMA Online Journal of Language Studies, 17(3), 18-36. http://doi.org/10.17576/gema-2017-1703-02

Brun-Mercer, N. (2019). Online Teaching Strategies for the Classrooms. English Teaching Forum, 57(4) 2-11 https://files.eric.ed.gov/fulltext/EJ1236175.pdf

Carioli, S. \& Peru, A. (2019) Teaching Online Reading Strategies Using the Think Aloud Technique. Evidence from an Experimental Study. Italian Journal of Educational Technology, 27(3), 279-294. https://doi.org/10.17471/2499-4324/1100

Chiazzese, G., Ohaviano, S., Merlo, G., Chifari, A., Allegra, M., Seta, L. \& Todaro, G. (2006). Metacognition in Web-Based Learning Activities. In: Mittermeir R.T. (eds) Informatics Education - The Bridge between Using and Understanding Computers. ISSEP 2006. Lecture Notes in Computer Science, Vol 4226. Springer, Berlin, Heidelberg. https://doi.org/10.1007/11915355_27

Coiro, J. (2011). Predicting reading comprehension on the Internet: Contributions of offline reading skills, online reading skills, and prior knowledge. Journal of Literacy Research, 43 (4), 352-392. https://doi.org/10.1177/1086296X11421979

Coiro, J \& Dobler, E. (2007). "Exploring the Online Reading Comprehension Strategies Used by Sixth- Grade Skilled Readers to Search for and Locate Information on the Internet. Reading Research Quarterly, 42(2), 214-57. https://doi.org/10.1598/RRQ.42.2.2

Hodgson, K. (2010). Strategies for online reading comprehension. Retrieved from https://learnc.org/lp/pages/6958. 
Hsin, Y. C. (2009). Online Reading Comprehension Strategies Among General and Special Education Elementary and Middle School Children. Retrieved from https://files.eric.ed.gov/fulltext/ED506429.pdf

Incecay, G. (2013). Metacognitive Online Reading Strategies Applied by EFL Students. Journal of Theory and Practice in Education, 9(4): 390-407.

Kymes, A. D. (2007). Investigation and Analysis of Online Reading Strategies. Phd Dissertation. Oklahoma State University.

Magogwe, J.M. (2013). Metacognitive Awareness of Reading Strategies of University of Botswana English as Second Language Students of Different Academic Reading Proficiencies. Reading \& Writing, 4(1). https://doi.org/10.4102/rw.v4i1.29

Mokhtari, K. \& Reichard, C. A. (2002) Assessing Students' Metacognitive Awareness of Reading Strategies. Journal of Educational Psychology, 4(2), 249-259. http://citeseerx.ist.psu.edu/viewdoc/download?doi=10.1.1.456.5716\&rep=rep1\&type=pdf

Mokhtari, K. \& Sheorey, R. (2002). Measuring ESL Students' Awareness of Reading Strategies. Journal of Developmental Education, 25(3), 2-10. http://doi.org/10.2307/42784357

Mudra, H. (2018). Metacognitive Online Reading Strategies among Pre-Service EFL Teachers in Indonesia. Educational Process: International Journal, 7(2), 151-164. Retrieved at http://dx.doi.org/10.22521/edupij.2018.72.

Naumann, J. \& Salmeron, L. (2016) Does Navigation Always Predict Performance? Effects of Navigation on Digital Reading are Moderated by Comprehension Skills. International Review of Research in Open and Distance Learning, 17(1) DOI: 10.19173/irrodl.v17i1.2113

Ostovar-Namaghi, S. A. \& Noghabi, A. E. (2014) A Comparison of Perceived Use of the Metacognitive Reading Strategies by Iranian Master of Science Students for Hypertext and Printed Academic Materials. Journal of Language Teaching and Research, 5(4) DOI: $10.4304 /$ jltr.5.4.865-872

Park, J., Yang, J. S. \& Hsieh, Y. C. (2014). University Level Second Language Readers' Online Reading and Comprehension Strategies. Language Learning \& Technology, 18(3), 148172.

Puntambekar, S., Sullivan, S. A. \& Hubshcher, R. (2013). Analysing Navigation Patterns to Scaffold Metacognition in Hypertext Systems. International Handbook of Metacognition and Learning Technologies, Springer International Handbooks of Education 26, 261-275. https://doi.org/10.1007/978-1-4419-5546-3_18

Raihana, R., Jamaludin, B., \& Nooreiny, M. (2017). Metacognitive Online Reading Strategies in Reading Academic Texts Among ESL University Students. Seminar on Transdisciplinary Education (STED 2017). Retrieved from https://sted2017.wordpress.com/proceeding/

Sheorey, R. \& Mokhtari, K. (2001). Differences in the Metacognitive Awareness of Reading Strategies among Native and Non-Native Readers. System. 29(4), 431-449. https://doi.org/10.1016/S0346-251X(01)00039-2

Stylianou, A. \& Puntambekar, S. (2003). How Do Students Navigate and Learn from Nonlinear Science Texts: Can Metanavigation Support Promote Learning? Retrieved from https://www.researchgate.net/publication/27404037_How_do_students_navigate_and_lea rn_from_nonlinear_science_texts_Can_metanavigation_support_promote_science_learni ng. 
Ulu, H. \& Ulusoy, M. (2019). The Development of Metacognitive Awareness of Reading Strategies Through WebQuest Based Teaching. Pegem Journal of Education and Instruction, 9(3), 765-818, http://dx.doi.org/10.14527/pegegog.2019.025

Vilhelmina, V. \& Užpalienè, D. (2013). Metacognitive Online Reading Strategies in Foreign Language Learning Context at University. Social Technologies, 3(2), p. 316-329 DOI: $10.13165 / \mathrm{ST}-13-3-2-06$

Walsh, A. \& Ollenburger, J. C. (2001) Essential Statistics for the Social and Behavioral Sciences: A Conceptual Approach. Boise State University: Pearson

World Internet Usage and Population Statistics: 2019 Year-End Estimates. (2020, March 3) https://www.internetworldstats.com/stats.htm

$\mathrm{Wu}$, J. Y. (2014). Gender differences in online reading engagement, metacognitive strategies, navigation skills and reading literacy. Journal of Computer Assisted Learning, 30(3), 252-271. http://doi.org/10.1111/jcal.12054

Zailani Jusoh \& Liza Abdullah. (2015). Online Survey of Reading Strategies (OSORS): Students' Online Reading in Academic Context. Malaysian Journal of Distance Education, 17(2): 67-81. doi: 10.21315/mjde2015.17.2.5 